\title{
El texto como objeto. Sobre la autonomía recuperada del texto dramático
}

Traducción del neerlandés: Catalina Cepernic

Fecha de recepción: 29/3/2021. Fecha de aceptación: 21/05/2021

\section{Resumen}

El objetivo de este trabajo es teorizar acerca de la relación entre texto y puesta en escena a través de un recorrido por diferentes maneras en las que el texto es trabajado en la escena en obras de teatro flamencas contemporáneas. En este sentido, el artículo plantea que a partir de estas prácticas en la escena posdramática, el texto teatral pierde jerarquía, pero a la vez se constituye como un objeto autónomo.

Palabras clave: teatro posdramático, puesta en escena, texto, suplemento, objeto de exposición

\section{The text as object. On the retrieved autonomy of the dramatic text}

\begin{abstract}
The aim of this article is to theorize about the relation between text and representation through the analysis of different ways in which the text is used on stage in contemporary Flemish theatre plays. In this sense, the article states that from these operations on the post-dramatic scene, the dramatic text loses hierarchy, but at the same time it is constituted as an autonomous object.
\end{abstract}

Keywords: post-dramatic theatre, representation, text, supplement, object of exposition

El presente texto fue publicado originalmente en: Swyzen y Vanhoutte (2011). Het statuut van de tekst in het post-dramatische theater. Amberes: ASP Editions, UPA. (pp. 105-114). Es una adaptación de una conferencia dada en el marco de las "VI Jornadas de doblaje y subtitulación de la Universidad de Alicante" con el título Surtitles as Performance, en noviembre de 2008. El autor agradece a Eva Blaute por la información sobre las prácticas de sobretitulación de Needcompany y MaisonDahlBonnema. 
De manera paradójica, la pérdida de autoridad del texto en el teatro posdramático ocurre, no pocas veces, de la mano de una aparición del texto como objeto en la representación. Hans-Thies Lehmann describe esta presencia del texto como objeto como la de un "cuerpo ajeno" que "se debe referir al texto como una cualidad de resistencia" (2013:259). Esto implica una dualidad: el texto parece oponerse a la representación visual, a la opsis, pero es en sí mismo también una forma de representación. Después de todo, debido a su naturaleza lingüística, el texto hace referencia a "un mundo externo a la escena" (Lehmann, 2013:146. N. de la T.: Las citas del texto de Lehmann son extraídas de la traducción editada por Paso de Gato, 2013, que representa en la escena).

En el teatro de habla neerlandesa podemos encontrar al texto dramático como objeto ya desde los años 80. La compañía Discordia puso en marcha en ese entonces un movimiento innovador al ubicar en primer plano la relación entre el actor y el texto. En este sentido, Discordia lleva a cabo presentaciones con apuntadores visibles en la escena, o en las que los actores revisan sus propios diálogos en el guion que tienen en sus manos. La compañía escenifica incluso espacialmente el hiato entre el texto y la representación, por ejemplo, en la obra Claus/Scribe (1988): los textos son fijados en el espacio en toda clase de elementos (sobre paredes, en el suelo, en el balcón). El texto está presente no solo de manera virtual, sino también de manera física, además los actores deben realizar esfuerzos por leerlo o encontrarlo (¡a veces con prismáticos!). Mediante el enfoque de Discordia, de gran influencia en los Países Bajos y en Flandes, el foco de la interpretación se desplaza desde un texto hacia el texto mismo. Los actores hacen referencia, a veces de manera literal, al papel en el que el personaje que interpretan fue creado por el autor (Hellemans y Geerts, 1996:53).

En el teatro posdramático, el texto se manifiesta cada vez más como un lenguaje tangible, como palabra e inclusive como objeto textual. A continuación, me interesa profundizar en las formas materiales en las que el texto teatral aparece en la escena. Más que nunca, se acentúa su carácter textual y aumenta en cierto sentido su autonomía con respecto a los demás signos teatrales. Examinaré algunas prácticas teatrales para probar esta hipótesis a partir de dos conceptos teóricos: suplemento y diálogo.

Tomaré como punto de partida las relaciones modificadas entre texto teatral y puesta en escena. Luego analizaré el funcionamiento de la lengua cuando es introducida en su capacidad plástica e ilustrativa y se desplazan los aspectos lingüístico-comunicativos. Estos dos movimientos no se excluyen entre sí, por el contrario, a veces se superponen.

\section{Relaciones entre texto y puesta}

Marvin Carlson describe cuatro relaciones posibles entre texto y puesta en escena (1985:5-11). En el primer caso, la puesta es una ilustración del texto: el texto forma un todo orgánico y es completamente autónomo. No puede agregarse nada ni es necesario hacerlo. La puesta en escena solamente cumple un objetivo didáctico para presentar de manera más atractiva las cosas difíciles (comparable a adaptaciones cinematográficas que se muestran en la escuela secundaria a modo de ilustración de obras literarias). La representación teatral no es esencial, porque esta función ilustrativa puede ser llevada a cabo a través de muchos dispositivos. El texto dramático se corresponde aquí en primer lugar con la categoría literatura y no con teatro.

La segunda relación posible es la de una traducción a otro dispositivo. En la semiótica teatral y también en estudios de adaptación es habitual la perspectiva de que un signo lingüístico (un texto) sea traducido a un signo de otra especie, pero equivalente (otro texto). Aquí también, el texto original es la fuente y, por lo tanto, lo más auténtico. La puesta en escena se encuentra incluida en el texto y es tarea del director desnudarla. 
El texto dramático conforma no solo el único punto de partida, sino también la finalidad de la puesta.

En la tercera relación posible, Carlson describe la representación como la consumación del texto dramático. Texto y representación forman juntos un todo orgánico. Un texto teatral necesita de la puesta en escena para cobrar vida. Así expresó Anne Ubersfeld la idea, todavía frecuente, de que un texto presenta vacios que son llenados por la puesta (1978), aun cuando define al teatro principalmente como una práctica escénica en lugar de literaria. La autora brinda su punto de vista con respecto al análisis literario tradicional -y a la vez una parte de su definición de teatro- en el comienzo del primer capítulo de L'école du spectateur: "Contrariamente a un prejuicio ampliamente instalado, cuyo origen se encuentra en la escuela, el teatro no es un género literario. Es una práctica escénica" (1981:9). Sin embargo, es indiscutible para Ubersfeld que en el origen de la puesta siempre se encuentra un texto:

... la puesta en escena más brillante del mundo no será más que un simple libro infantil con dibujos si no se sostiene en la fuerza del texto (y no nos referimos aquí a los diálogos). Así como el error de las puestas actuales es confiar por completo en la escenografía y en los actores; el error de los textos como "creación colectiva" es que les falta la fuerza de una instancia de escritura.

Según Ubersfeld, el teatro consiste en la interacción necesaria entre dos sistemas de signos: un sistema que tiene que ver con la representación y un sistema lingüístico, el texto dramático.

Carlson define además una cuarta relación posible: la puesta como suplemento del texto, un concepto que toma de Jacques Laporte y Jacques Derrida. En ese caso, la puesta se entiende como un agregado al texto, que influye sobre él. Carlson utiliza el conocido ejemplo ya citado por Laporte de los suplementos que se agregan a una enciclopedia cuando hay contenido obsoleto que necesita ser actualizado. Laporte plantea que la relación entre la enciclopedia y su suplemento es de carácter recíproco. En palabras de Carlson: "Obliga a adaptar la percepción y dirigirla en ambos sentidos" (1985:20). Después de todo, el suplemento nos hace tomar conciencia de las lagunas presentes en el original, que sin embargo parecen inevitables y necesarias. La diferencia con los vacíos de Ubersfeld yace precisamente en esa conciencia: el suplemento -en este caso la puesta en escena- hace visibles lagunas que ni siquiera percibíamos. Los huecos en la mirada de Ubersfeld son detectables, como la pregunta sobre cómo es el aspecto de un personaje que no es descrito. A medida que se llenan los vacíos del texto, adquirimos la sensación de que la puesta es completada. Sin embargo, la puesta como suplemento crea la perspectiva de que ella nunca puede ser la finalidad: pueden agregarse interminablemente muchos suplementos (otras puestas en escena). Desde el punto de vista de la representación como suplemento, aquella establece un diálogo con el texto. Esto concuerda con la idea posdramática de que el texto es solo uno de muchos elementos en un todo mayor y que pierde su estatus superior dentro de la jerarquía del teatro. Después de todo, el texto es completado y corregido. Considerado de manera ontológica, el texto impreso representa, entonces, solo una de las muchas realizaciones posibles del manuscrito y ya no constituye la versión de autoridad, el punto de partida de la puesta y hacia el cual ella finalmente regresa. Es importante destacar que en los estudios teatrales anglosajones (además de la evolución hacia los performance studies, que también desvinculan texto y representación), el texto dramático a menudo es relacionado con la autoridad del autor, mientras que la "muerte del autor" (Barthes, Foucault) hace que los textos parezcan perder todo fundamento de autenticidad (Foakes, 2006; una réplica en: Worthen, 2006; Saltz, 2001). 


\section{Diálogo sobre el escenario heteroglósico}

Los conceptos suplemento y diálogo no solo arrojan luz sobre la relación modificada entre puesta y texto en el teatro posdramático. También son instrumentos para describir el impacto del uso de sobretítulos en una representación. El concepto de diálogo es utilizado aquí en el sentido que Mijaíl Bajtín le otorga. En su teoría es casi un sinónimo de intertextualidad, la idea de que los textos están en relación unos con otros y se comentan entre sí. En Speaking in tongues, Marvin Carlson estudia, a partir del concepto "heteroglosia" de Mijaíl Bajtín, cómo las lenguas "juegan juntas" en la escena: "las muchas maneras en las que las lenguas ... se han cruzado entre sí en una multiplicidad de contextos teatrales distintos, y algunas implicancias de estos cruces en términos de recepción, mímesis y la inserción social, política y cultural de la puesta teatral." (2006:5-6). Carlson toma el concepto de Bajtín a través de un rodeo: desde el influyente estudio etnográfico-cultural de James Clifford The Predicament of Culture (1988), en el que este último desarrolla el término. Partiendo de este marco del escenario heteroglósico, la práctica de puestas sobretituladas puede ser entendida como una representación polifónica en la que actúan diferentes "lengua(je)s". Esto quiere decir que, en el carácter heteroglósico de una representación teatral, el uso de diferentes lengua(je)s hace emerger formas dialógicas de comunicación. El diálogo se desarrolla entre las distintas lenguas en escena, pero también entre escena y público.

En un análisis del sobretitulado en la representación de King Lear (2000) de Needcompany, Carlson señala la interacción entre el texto original (y completo) de Shakespeare, tal como aparece en los sobretítulos, y las acciones en la escena. Una versión reducida del análisis puede encontrarse en Carlson (2007). Los intérpretes reaccionan ante el sobretitulado que, por supuesto, también es visible y legible para el público. Por ejemplo, la escena en la que Gloucester es enceguecido es anunciada por un actor con las palabras "Trying to do this next scene onstage is a total fucking joke". En otros momentos, los actores no actúan en función de los sobretítulos. En el notorio acto V, por ejemplo, el bufón menciona los nombres de los personajes que deberían tomar la palabra (Dirk Roofthooft, que interpreta al bufón, sostiene además el guion en sus manos para seguir el texto). Aquí, el roce entre el texto original y el texto interpretado es concreto y visible. Una práctica posdramática implica desconfiar de la existencia de una voz neutral y de un movimiento predestinado, lógico desde la fuente hacia el resultado. En el teatro de Needcompany, en un sentido riguroso, el sobretitulado es una traducción de la lengua de origen a la lengua de llegada. Pero durante la puesta en escena, ambas lenguas son perceptibles de manera simultánea y sus contextos culturales cumplen un rol. ${ }^{1}$ En el ejemplo que cita Carlson, no se trata tampoco de una duplicación ni de variantes de enunciados (heteroglosia en un sentido estrictamente lingüístico). La traducción construye justamente un nivel de sentido (o de significado) por encima de los demás niveles. Los sobretítulos no son para nada inocentes o neutrales. Representan una interpretación, el resultado de decisiones tomadas por el traductor (con autorización del autor original o sin ella). Son utilizados "no solo como portadores transparentes de otros lenguajes teatrales, sino como lenguajes con una razón de ser propia, con capacidad de transmitir sus propios mensajes, que podrían funcionar como suplemento de, o establecer diálogos con otros lenguajes sobre el escenario" (Carlson; 2006:18; la cursiva es nuestra). ${ }^{2}$

1 La poca investigación disponible en este campo refiere a menudo a los sobretítulos para ópera. Ver, por ejemplo: Mateo (2007). En su contribución en las “VI Jornadas de doblaje y subtitulación de la Universidad de Alicante" (noviembre de 2008) llamó a este uso de los sobretítulos "nuevo y provocativo".

2 Probablemente en este punto sea evidente para el lector que el término "lenguaje" cubre un amplio campo de significaciones, se trata tanto de lenguaje teatral como de cualquier sistema de comunicación que utiliza signos dispuestos de una manera determinada (cotejar los estudios de Lotman, Ubersfled, Pavis, pero sobre todo de Marinis, 1993). 


\section{El suplemento en los dos sentidos de la palabra}

En su exposición sobre el suplemento, Derrida enfatiza el -a primera vista contradictorio- doble significado del término. Comenzaremos por el segundo significado, quizás menos evidente: "El suplemento reemplaza. Se agrega únicamente para reemplazar. Interviene o se infiltra para tomar el lugarde; completa algo, así como se llena un vacío." (Derrida; 1967: 208). En el contexto de los sobretítulos, la traducción constituye un suplemento de manera literal: el sobretítulo (escrito) toma el lugar de la lengua (hablada) de origen. Así, el público puede comprender la puesta en escena. Si bien la definición de suplemento también es aplicable en el caso del doblaje o de la traducción simultánea, el doble significado del término se hace realmente evidente solo en el caso de los sobretítulos. Después de todo, según Derrida, el primer significado implica que el suplemento "se agrega, es un excedente, una abundancia que enriquece a otra abundancia, es el colmo de la presencia" (1967: 208). Las dos versiones del texto coexisten; no como "complemento" una de la otra, sino como "suplemento", como "agregado externo" (Derrida; 1967: 208), añadido desde el exterior, así como también los sobretítulos generalmente se ubican fuera del marco escénico. El original necesita del suplemento (la traducción) para poder llegar al público. Además, el espectador que domina no solo la lengua de llegada sino también la lengua de origen (esta última, completamente o en parte), obtiene un excedente. Cuando la obra se lleva a una gira internacional, las diferentes traducciones hacen surgir además una serie de variantes; lo que dificulta señalar una original y también hace que la idea de unicidad de la representación se vea amenazada.

El concepto del suplemento no solo es relevante para la diferencia entre dos o más lenguas, sino también para la diferencia entre lengua escrita y lengua hablada. El sobretítulo reemplaza o representa la palabra hablada y es por esto que es “...extraño frente a lo que debe ser distinto a él para poder ser reemplazado." (Derrida; 1967: 208). Tradicionalmente, durante una puesta en escena, el espectador intenta, en la semiosis, ignorar la traducción. Pero, como señala Carlson, hoy en día los sobretítulos aparecen a menudo "...de manera más directa en el marco estético de la puesta ... [y] de esta manera añaden lenguajes complementarios a la escena heteroglósica." (2006: 181). Los sobretítulos agregan significados e interpretaciones suplementarias al texto dramático original y se vuelven una parte integral de la escena. A veces, el sobretítulo se integra incluso de manera explícita como un texto significante. De esta manera, el texto adquiere el carácter de objeto, de cuerpo extraño.

\section{Juego con los sobretítulos}

En The ballad of Ricky and Ronny (2007) de MaisonDahlBonnema (asociada con Needcompany), los sobretítulos de un fragmento cantado en inglés se proyectan sobre una pantalla que forma parte de la escenografía en una sala de estar. En otras palabras, los sobretítulos se encuentran incluidos en el marco visual. Además, es visible en la escena el manejo del proyector por parte de la traductora, que hace el papel de mucama en la obra. Los sobretítulos aparecen siempre duplicados: el texto original en inglés debajo de la traducción al neerlandés, francés, español, alemán u otro. Como consecuencia, el espectador dispone en todo momento de tres versiones: el texto cantado en inglés, el texto escrito en inglés y la traducción (que está hecha, en principio, a su lengua materna). Estas tres versiones quizás dicen lo mismo, pero a menudo significan cosas diferentes. En un momento dado, el personaje Ronny canta melodiosamente "Fuck you, Ricky". Eso aparece también sobretitulado, tanto en inglés como en la otra lengua. En francés se traduce a "Va te faire foutre, Ricky", o en español a "Que te jodan, Ricky", que para la mirada y el oído de un hablante de inglés (o neerlandés) tienen un efecto rítmico muy diferente que la variante original inglesa de solo dos sílabas. 
En el neerlandés, por su parte, la frase ¡no se traduce!, simplemente aparece otra vez "Fuck you, Ricky". El hecho de que en esta lengua estemos tan acostumbrados a usar este insulto en una lengua extranjera, produce una distancia evidente con respecto a los significados y connotaciones ofensivas y humillantes que seguramente sí están presentes para los hablantes nativos (y también en las demás lenguas/traducciones). El contraste entre el fuck you melodiosamente cantado y el fuck you - digamos- seco del suplemento escrito en la pantalla produce un efecto de extrañamiento. La tensión entre el sonido, la palabra escrita y la traducción pone de relieve la manera en la que los personajes se relacionan entre sí. La construcción de sentido por parte del espectador deriva del carácter dialógico de los textos heteroglósicos: todos dicen exactamente lo mismo, pero de maneras diferentes. Según Lehmann, la presencia simultánea del sonido y la palabra escrita tiene además como consecuencia que “... la palabra no pertenece al hablante; no habita orgánicamente en el interior de su cuerpo, sino que sigue siendo parte de un cuerpo ajeno." (2013:263). De esta manera el texto no solo se desvincula de su escenificación, sino también de los personajes que lo enuncian.

En el Koninklijke Vlaamse Schouwburg [Teatro Real Flamenco] de Bruselas (KVS, por sus siglas en neerlandés), se intenta que todas las obras presenten sobretítulos si es posible en inglés, además de en la otra lengua oficial [N. de la T.: el autor se refiere aquí a las dos lenguas más importantes de las tres que son oficiales en Bélgica: el francés y el neerlandés]. Además, en consonancia con la perspectiva del KVS acerca del lugar que debe ocupar un teatro contemporáneo en una sociedad multicultural, en este caso Bruselas, en muchas obras se habla tanto neerlandés como francés. Los sobretítulos constituyen a menudo una mezcla de ambas lenguas. En su archivo de solicitud de subsidios, el KVS menciona explícitamente: "Sobretitular tiene consecuencias artísticas, que idealmente deben ser tenidas en cuenta desde el primer día del proceso de producción." (KVS, 2009:23). Las consecuencias artísticas pueden tener que ver con limitaciones escenográficas, pero sin dudas también con la integración en la puesta en escena en sí. Revue (2008) fue una obra que ponía el foco en la situación política de Bélgica y, por lo tanto, también sobre la problemática de la vida en comunidad. En un momento dado, el actor/personaje Willy Thomas pide que los sobretítulos en francés sean interrumpidos para poder decir cosas malas sobre el público francófono, sin que este pueda comprender del todo lo que el actor dice. Esta operación evidencia, en primer lugar, que el actor/personaje es consciente del hecho de que hay sobretítulos que están siendo proyectados. En la práctica teatral actual de los Países Bajos, interpretar a un personaje de esta manera, consciente de símismo, no es nada fuera de lo común. En este actuar posdramático, el actor sigue presente en el personaje que interpreta y no lo abandona luego de comentarlo (y, por lo tanto, de salir de su papel). Las convenciones del formato revue [palabra en neerlandés para "teatro de variedades" o "varieté"] permiten realizar estas intervenciones de manera sencilla. En segundo lugar, este juego con los sobretítulos implica una referencia al contexto social. Con él se hace referencia a lugares comunes acerca de los habitantes francófonos de Bélgica, particularmente el hecho de que no dominan el neerlandés. Al bloquear un canal de comunicación, el intérprete excluye a un sector específico del público. Es la ilustración de un juego de poder, ilustración posible gracias a una región que pone en juego los sobretítulos deliberadamente, en medio de la situación de heteroglosia que se da tanto dentro de la escena como dentro de la sala.

\section{El texto como cuerpo extraño}

En producciones de compañías internacionales itinerantes como Needcompany, los sobretítulos son algo propio y normal. Sin embargo, con The Lobster Shop (2006), la compañía los incorporará también como un elemento visual en la puesta en escena. La traducción aparece en una pantalla que también es utilizada para proyectar 
tomas cinematográficas, ubicada detrás del escenario. No hay duplicación del texto hablado o cantado porque casi siempre cada actor del elenco internacional usa su propia lengua, y los sobretítulos están exclusivamente en la lengua de llegada (la del público). Lehmann plantea que "Lauwers establece un espacio conjunto de problemas lingüisticos en el cual tanto los actores como los espectadores experimentan los bloqueos de la comprensión lingüística." (2006:263). De ahí el hecho poco común de que los fragmentos de texto no sean proyectados en una fuente gráfica neutral. En algunos de ellos las palabras se muestran más grandes, por ejemplo, cuando un personaje enfatiza una línea o habla más fuerte. Las letras también pueden adoptar otras formas tipográficas. Cuando se habla de Jimi Hendrix, los sobretítulos se presentan en un estilo pop de los años 6o. Desde el aspecto semiótico, la sobretitulación se pone en juego como un elemento visual en el texto dramático, como una imagen entre las otras imágenes. Es por esto que los sobretítulos adquieren un carácter más autónomo con respecto al texto del cual son una traducción. ${ }^{3}$ Ya no se trata de la traducción, sino del carácter material y tangible de las letras, palabras autónomas que ya no pertenecen en absoluto a aquel que las pronuncia.

\section{Cuerpos que devienen lengua}

En Lex (2008) de Peter Verhelst, una figura dice (y canta) líneas en diferentes lenguas. Los sobretítulos no muestran una traducción, sino que duplican el texto interpretado. Para el espectador no es del todo claro quién es esta figura enmascarada en la penumbra. Podría decirse que el personaje encarna al texto. Hacia el final de la puesta, el texto se acelera y es proyectado en espejo sobre la cabeza del actor. Este texto ya no opera como sobretítulo; se acomoda a la forma de la cabeza. Más aun, es la única manera en la que la cabeza puede percibirse. El cuerpo deviene lengua, o la lengua deviene cuerpo.

En algunas obras de Guy Cassiers, el texto proyectado también supera su función de suplemento. En Rotjoch (1998), todas las figuras, excepto por el personaje principal Pim Parel, aparecen únicamente como una proyección de palabras. La crítica Marijn Van der Jagt lo describe de una manera muy ilustrativa:

Llegan volando como si fueran palabras que deja la estela de una avioneta. Atraviesan el espacio desplazándose tímidamente, o invaden la pantalla completa como el aire que infla un globo. Las palabras se amplían, se acercan con prudencia o se alejan irritadas. Son discretas o inoportunas en su punto justo, furtivas o estruendosas. [...] Papá es un conjunto estridente de mayúsculas, que se elevan sobre Pim llenando la imagen. La entrometida señora Zeikstra es un trazo cursi, pomposo, como pasteleros que se drogan. [...] Así, de cada personaje del mundo que rodea a Pim, se construye un ícono, una grafía que con su forma cuenta en sí misma una historia completa (1998).

Aquí, los personajes cobran vida, exclusiva y literalmente, a partir de la lengua.

\section{¿Emancipación del texto?}

Por lo general, las palabras son signos que refieren a otra cosa, a objetos materiales del mundo. En el caso de los sobretítulos, refieren también a palabras que son pronunciadas en la puesta en escena (y viceversa, porque ambas están presentes de

3 Irónicamente, el texto que se proyecta como sobretítulos es el texto original en sí mismo y por ende, no es una traducción. Esta es expresada por los actores. Eso, por supuesto, no lo sabe uno como espectador. (Información tomada de una conversación con Eva Blaute, integrante de la compañía). 
manera simultánea, visibles y audibles). Pero las palabras (proyectadas) en una puesta también pueden devenir objetos: refieren a sí mismas y ya no al locutor ni a algo más en el mundo exterior. Como signos teatrales, ya no funcionan como "un signo de un signo", sino puramente como un signo de sí mismas. La afirmación de que una representación teatral consiste en un juego de signos y de signos que refieren a signos fue formulada originalmente por Petr Bogatyrev en los años 30 del siglo pasado (1976).

Dado que las palabras son visibles en sí mismas, sustituyen además a las palabras en papel en el texto dramático. Este último recupera entonces su autonomía, porque puede existir por fuera de la puesta. No es casual que resuenen voces que exigen otra vez esa cualidad literaria al texto teatral. Es así que Stefan Hertmans, en su disertación en el Premio a la Dramaturgia de la Unión de la Lengua (Taalunie), alega en favor de la publicación de obras de teatro. (Hertmans 2002; 2006). Su solicitud recibe respuesta a través de iniciativas como el Schrijverspodium [Podio de Escritores] o la Nieuwe Toneelbibliotheek [Nueva Biblioteca Teatral]. La manera en la que se trabaja con el texto en la representación posdramática, significa, por extraño que parezca, una emancipación del texto como texto. 


\section{Dibliografía}

» Bogatyrev, P. (1976). “Semiotics in the Folk Theater". En Matekja, L. y Titunik, I. (ed.), Semiotics of Art: Prague School Contributions. (pp. 33-50). Cambridge: MIT Press.

"Carlson, M. (2007). “Needcompany's King Lear and the Semiotics of Supertitles". En Stalpaert, C., Le Roy, F. y Bousset, S. (ed), No beauty for Me There Where Human Life is Rare: On Jan Lauwers' Theatre Work with Needcompany. (pp. 188200). Gent: Academia Press, International Theatre and Film Books.

"Carlson, M. (2006). Speaking in Tongues: Languages at Play in the Theatre. Ann Arbor: University of Michigan Press.

»Carlson M. (1985). "Theatrical Performance: Illustration, Translation, Fulfillment, of Supplement?". Theatre Journal 37, 5-11.

»Clifford, J. (1988) The predicament of Culture: Twentieth-Century Ethnography, Literature and Art. Cambridge: Harvard University Press.

»De Marinis, M. (1993). The Semiotics of Performance. Bloomington: Indiana University Press.

»De Nieuwe Toneelbibliotheek. Consultado el 3 de abril de 2011 en http://www. denieuwetoneelbibliotheek.nl/books

»Derrida, J. (1967). De la grammatologie. París: Éditions de Minuit.

»Foakes, R. A. (2006). "Performance Theory and Textual Theory: A Retourt Courteous". Shakespeare 2.1, 47-58.

» Hellemans, D. y Geerts, R. (1996). "A Survey of Some Tendencies in Recent European Theatre and Dance". En Hellemans, D. y Geerts, R. (ed.), Unwitting Influences in Theatre. (pp. 31-61). Bruselas: VUBPress.

" Hertmans, S. (2002). “Acteur versus auteur” en Het putje van Milete. (pp. 211229). Ámsterdam: Meulenhoff.

» Hertmans, S. (2006). “Toneelschrijfprijslezing”. Disponible en: https://www. denieuwetoneelbibliotheek.nl/nieuws/2009/11

》 KVS. "KVS. Aanvraag meerjarige subsidie voor het geheel van het periode 20102012". Consultado el 8 de abril de 2011 en http://www.kvs.be/inc.content/subsidiedossier_nl.pdf

»Lehmann, H. T. (2013). Teatro Posdramático. Ciudad de México: Paso de Gato. Trad. Diana González.

" Mateo, M. (2007). "Reception, Text and Context in the Study of Opera Surtitles". En Gambier, Y., Schlesinger, M. y Stolze, R. (ed.), Doubts and Directions in Translation Studies. (pp. 169-182). Ámsterdam: John Benjamis.

»Saltz, D. Z. (2001). "What Theatrical Performance Is (Not): The Interpretation Fallacy". The Journal of Aesthetics and Art Criticism 59.3, 299-306.

»Schrijverspodium. Consultado el 3 de abril de 2011 en http://www.schrijverspodium.be/

"Ubersfeld, A. (1981). L'école du spectateur. París: Éditions Sociales.

»Ubersfeld, A. (1978). Lire le théâtre. París: Éditions Sociales. 
» van der Jagt, M. (1998, 12 de junio). “Het woord is karakter geworden”. En De Volkskrant.

»Worthen, W. B. (2006) “A Quip Modest: Reply to R.A. Foakes's 'Performance Theory and Textual Theory". Shakespeare 2.2, 208-219. 